\title{
Fruit size QTLs affect in a major proportion the yield in tomato
}

\author{
Aurelio Hernández-Bautista ${ }^{1}$, Ricardo Lobato-Ortiz ${ }^{1 *}$, Serafín Cruz-Izquierdo ${ }^{1}$, \\ J. Jesús García-Zavala ${ }^{1}$, José Luis Chávez-Servia ${ }^{2}$, Enrique Hernández-Leal ${ }^{1}$, \\ and Olga Bonilla-Barrientos ${ }^{1}$
}

Yield is a complex trait that is affected by several genetic and environmental factors. Yield is defined as the amount of the part of interest that is harvested from a crop plant in a given area. We investigated the genetic basis of yield in an $\mathrm{F}_{2}$ population derived from a cross between Solanum lycopersicum L. and its most closely related wild species S. pimpinellifolium L. We found that average fruit weight, fruit diameter, and fruit length had a strong effect on yield. In addition, small effects on yield due to soluble solids content and locule number were also observed. A total of 25 different significant quantitative trait locus (QTLs) were detected for six traits (fruit length and diameter, fruit weight, yield, locule number, and Brix degrees). The percentage of phenotypic variation associated with single QTLs ranged from $4.19 \%$ to $12.67 \%$. A strong co-location of QTLs among yield and fruit size traits was observed, suggesting that these QTLs play a role in the same expression process controlling yield. We also realized that the effects of soluble solids content on yield could be due to direct effects of fruit size QTLs linked to genes controlling soluble solids content. This result then may suggest that yield in tomato is mainly formed by fruit size QTLs, whereas the remaining factors may play a complementary role in the expression of tomato yield.

Key words: Fruit size, locule number, QTL, Solanum lycopersicum, soluble solids content, tomato.

\section{INTRODUCTION}

Recently, a dramatic increase in yield has been observed on major food crops of the world over the past $70 \mathrm{yr}$, this is mainly due to a combination of the role of plant breeding, mechanization, and improved management practices. Yield of forage, grain, fiber, or other plant products has primary importance as a breeding objective because it is directly related to the economic return to the grower. This trait is expressed phenotypically through complex interaction of biochemical and physiological processes (photosynthesis, respiration, translocation, and transpiration). These processes are affected by genetic factors that interact with the environment in which the plant genotype is grown (Poehlman and Sleper, 1995).

Yield is defined as the amount of the part of interest that is harvested from a crop plant in a given area at the end of the cropping season or within a given period of

${ }^{1}$ Colegio de Postgraduados, Campus Montecillo, km 36.5 carretera México-Texcoco, 56230, Texcoco, Edo. de México, México. *Corresponding author (rlobato@colpos.mx).

${ }^{2}$ Instituto Politécnico Nacional, Centro Interdisciplinario de Investigación para el Desarrollo Integral Regional, Unidad Oaxaca (CIIDIR), Hornos 1003, 71230, Santa Cruz Xoxocotlán, Oaxaca, México.

Received: 20 December 2014.

Accepted: 25 April 2015.

doi:10.4067/S0718-58392015000500004 time. The plant part of interest is that one for which the crop producer grows the crop. It could be leaves, fruits, stems, roots, or flowers, or any other morphological part. It could also be the chemical content of the plant such as oil, sugar, or latex (Acquaah, 2007). Biological yield may be measured by breeding for physiological and morphological traits. To increase yield, the breeder may breed for increased biomass and efficient partitioning of assimilates (Poehlman and Sleper, 1995). The potential biomass of a crop is determined by factors including genotype, local environment (soil, weather), and the agronomic practices used to grow it (Acquaah, 2007).

To date, tomato (Solanum lycopersicum L.) yield increases have been obtained directly by increasing the harvest index, and also indirectly by improving the potential production through the resistance or tolerance to biotic or abiotic stresses. This success is due to the correct combination of the different yield components. Thus, varieties that produce up to $15 \mathrm{~kg} \mathrm{~m}^{-2}$ and with a high percentage of commercial yields have been developed (Diez and Nuez, 2008).

In tomato, the yield is determined by total biomass production, biomass partitioning, and fruit DM content. Besides affecting the amount of the crop, these attributes also influence product quality. Biomass production is primarily driven by photosynthesis, which depends on light interception and leaf area (Heuvelink and Dorais, 2005). However, a high biomass production does not 
necessarily result in a high yield, since only the tomato fruit is of economic interest. Other important parameter is fruit DM content, since this parameter determines which fresh fruit mass results from the dry mass partitioned into the fruit (Heuvelink and Dorais, 2005).

Various attempts have been made to manipulate the yield in tomato. One approach to hand this complex trait is the design of a path by which the developmental and morphological traits of the plants contribute to the yield. The pathways to yield are collectively named yield components. Using these components, breeders would understand the strength of correlated traits that would assist in the decision making process to select for more than one character (Monamodi et al., 2013). In tomato, different yield components affecting yield have been identified. Some of these components include traits such as fruit set, fruit weight (Rashidi et al., 2009), total number of truss, number of flower per truss, and fruit number per truss (Monamodi et al., 2013). In addition, developmental processes such as inflorescence formation, flower development and fruit ripening also have a strong impact on tomato yield (Heuvelink and Dorais, 2005). Another factor directly affecting tomato yield is fruit formation process, since the final fruit size depends on the number and volume of cell layers in the pericarp of the fruit, which are determined by the degree of cell division and expansion in the fertilized ovaries. Thus, fruit yield in tomato is determined by the efficiency of fruit set and the final cell number and size of fruits (Ariizumi et al., 2013).

Traditional breeding studies suggest that the genetic control of fruit size is not very complex. In fact, classical genetics has shown that at least 5-6 genes govern the trait, which allowed that its management into plant breeding programs had been easy (Fogle and Currence, 1950). With the advent of molecular markers, it has become possible to associate genome regions containing these markers to variation in complex traits (Hall et al., 2010). In tomato, numerous quantitative trait locus (QTL) mapping studies have been conducted to determine the number, location, dominance degree and genetic effects of the loci controlling quantitative traits. This have led the identification of different sets of QTLs on inter-specific mapping populations conformed by $S$. lycopersicum and $S$. pimpinellifolium L. (Grandillo and Tanksley, 1996; Chen et al., 1999; Doganlar et al., 2002), where most of the QTL controlling fruit size were identified in chromosomes 1,2 , $3,4,6,7$, and 11. Additionally, important genes governing fruit shape and size were cloned using fine mapping. $F W 2.2$ is known to largely govern fruit size (Ariizumi et al., 2013). SUN and OVATE control elongated shape, whereas $F A S$ and $L C$ determine the final locule number (Rodríguez et al., 2011; Muños et al., 2011).

To date, our understanding about the domestication of cultivated tomato has archived a considerable progress due to molecular information generated during the last three decades. Nevertheless, a significant minor impact has been observed in the field of plant breeding on complex traits such as yield. For example, several QTLs affecting yield have been identified in tomato using different interspecific populations (Eshed and Zamir, 1995; Bernacchi et al., 1998; Frary et al., 2004). However, their use for marker-assisted selection is little. Furthermore, these QTLs present a limited concordance across studies, which show the difficult to identify QTLs that may be truly indicative of genetic yield potential (Foolad, 2007).

In this study, we investigated the genetics basis of yield in an $\mathrm{F}_{2}$ population derived from a cross between a Mexican native accession of S. lycopersicum named LOR82 and its most closely related wild species ( $S$. pimpinellifolium). The study revealed the presence of 25 QTLs, 17 of which affected directly yield. All QTLs identified for yield colocated with QTLs for fruit size, indicating that fruit size QTLs play a role in the developmental process controlling yield. In addition, our results also revealed a major effect of fruit size traits on the expression of yield.

\section{MATERIALS AND METHODS}

\section{Plant material}

An interspecific cross between $S$. lycopersicum accession LOR82 and S. pimpinellifolium accession 11904 was made to produce $F_{1}$ seeds. A single interspecific $F_{1}$ hybrid was selfed to produce an $\mathrm{F}_{2}$ population suitable for molecular mapping. A total of $159 \mathrm{~F}_{2}$ plants, 20 of each parental control, and $20 \mathrm{~F}_{1}$ plants were grown twice using seed and clones in the greenhouse facilities at the Colegio de Postgraduados, Mexico, during spring/ summer and summer/fall seasons in 2012, respectively. At both seasons, the $\mathrm{F}_{2}$ experiments were conducted in a completely randomized design.

\section{Phenotyping}

Each of the parent-type plants and the $F_{1}$ and $F_{2}$ plants were characterized phenotypically for six quantitative traits during two seasons. At the end of the growing seasons, five representative ripened fruit were harvested from each plant for measurements of some fruit-size related traits and quality. Average fruit weight (FW, g) was calculated measuring five fruits per plant. The same subset of five fruits was used to obtain the average per plant for fruit diameter and fruit length. Fruit diameter (FD, mm) was obtained from averaging the perpendicular measurements taken of the same five fruits. Fruit length (FL, mm) was calculated as the mean length, obtained from the stem to the blossom end from each fruit. Five harvested fruits were cut transversely to count and calculate the average locule number (LN) per plant. The mixed fresh juice of the same five fruits was used to determine the total soluble solids concentration (SSC, ${ }^{\circ}$ Brix). Total yield (TY, g) was scored as the total weight, of all fruits produced per plant. 


\section{Genotypic analysis}

A modified cetyltrimethylammonium bromide (CTAB) method was employed to extract genomic DNA from each of the parents and $159 \mathrm{~F}_{2}$ plants, as described by Bernatzky and Tanksley (1986). Sixty simple sequence repeat (SSR) markers covering all chromosomes were chosen from Tomato Mapping Resource Database (http://164.107.85.47:8003/) and Sol Genomics Network (http://solgenomics.net/) based on their map positions. PCR amplification and SSR genotyping were carried out as described by Creste et al. (2001). Of the 60 SSR markers, 31 were polymorphic between the two parents and were used for genetic mapping in the $F_{2}$ population evaluated on spring/summer season 2012.

\section{Statistical analyses}

Marker segregation was tested for significant deviation from the expected ratio of $1: 2: 1$ by the $\chi^{2}$ test. Linkage analysis of the 31 markers on the 12 tomato chromosomes was performed using the software package MapDisto 1.7.7 (Lorieux, 2012). A logarithm of odds ratio (LOD) of 3.0 was established to consider significant linkage. Recombination frequencies were converted into map distances (cM) using the Kosambi mapping function (Kosambi, 1944). The linkage groups were localized in function to the genetic map proposed by Robbins et al. (2011).

Means, Normality (Shapiro-Wilk) and Tukey tests, Pearson correlation coefficients and yield components were calculated for each trait using $\mathrm{R}$ software version 3.0.1 (R Core Team, 2013). QTLs were identified by both a single-point regression analysis (SMA) and composite interval mapping (CIM) (Zeng, 1994) using Windows QTL Cartographer 2.5 (Wang et al., 2012). Threshold was obtained by permutation test using 1000 permutations. The LOD threshold was set from 2 to 2.5 for interval analysis, and a $p<0.004$ value was set for single-point linear regression analysis. The percent of phenotypic variance explained by a QTL (R) was obtained from QTL Cartographer. A multiple linear regression using $\mathrm{R}$ software was performed to estimate the percentage of phenotypic variation accounted for various combinations of significant QTLs. The degree of dominance of the alleles at a given locus was expressed as $|d / a|$, where $d=$ (LP) $-1 / 2(\mathrm{LL}+\mathrm{PP})$, and $a=(\mathrm{LL})-1 / 2(\mathrm{LL}+\mathrm{PP})$, where LL is phenotypic value for homozygous $S$. lycopersicum, $\mathrm{PP}$ is phenotypic value for homozygous $S$. pimpinellifolium, and LP is phenotypic value for the heterozygote. Additive gene action was declared when $|d / a|<0.2$, while values of 0.2 $\leq|d / a|<0.8$ and $0.8 \leq|d / a|<1.2$ meant partial dominance and completed dominance, respectively. Gene action of $|d / a| \geq 1.2$ indicates overdominance (Stuber et al., 1987). Interaction between two QTLs was determined via twoway ANOVA using an R program. Broad-sense heritability $\left(\mathrm{H}^{2}\right)$ was estimated from one-way random-effects of ANOVA with the equation $\mathrm{H}^{2}=\sigma_{\mathrm{g}}^{2} /\left(\sigma_{\mathrm{g}}^{2}+\sigma_{\mathrm{e}}^{2} / b\right)$, where $\sigma^{2}$ is the genotypic variance, $\sigma^{2}{ }_{\mathrm{e}}$ is the environment variance and $b$ the number of replicates per genotype.

\section{RESULTS}

A total of six quantitative traits such as average fruit weight (FW), fruit length (FL), fruit diameter (FD), locule number (LN), total soluble solids concentration (SSC), and total yield (TY) were evaluated in this study. The parents differed significantly $(p \leq 0.05)$ for all the traits studied, with S. lycopersicum (SL) parent having higher trait values than $S$. pimpinellifolium (SP) parent for all traits, except for SSC, for which SP showed a higher value than cultivated tomato (Table 1). In addition, there were not significant differences for those traits between $F_{1}$ and $F_{2}$ population means. The phenotypic distribution of the $\mathrm{F}_{2}$ progeny showed continuous variation for most of the yield-related traits, suggesting that they were under quantitative and polygenic control. Finally, transgressive segregation was observed in the progeny for the traits SSC, TY, FW, FD, and FL.

\section{Changes over time of traits and their Genotype $x$ Environment interaction}

Different amounts of variation were observed among the horticultural traits over time. Average FW showed variation over the two phenotypic evaluations. In the first season, genotypic values of $128.1,0.7,6.2$, and $8.4 \mathrm{~g}$ were obtained for S. lycopersicum, S. pimpinellifolium, $\mathrm{F}_{1}$,

Table 1. Mean phenotypic values, standard deviations for parents $F_{1}$, and $F_{2}$ population.

\begin{tabular}{|c|c|c|c|c|c|c|}
\hline & Solanum lycopersicum & S. pimpinellifolium & $\mathrm{F}_{1}$ & $\mathrm{~F}_{2}$ & & \\
\hline Trait & Mean \pm SD & Mean \pm SD & Mean \pm SD & Mean \pm SD & MSD & P-value \\
\hline $\mathrm{FW}, \mathrm{g}$ & $120.77 \pm 39.82 \mathrm{a}$ & $0.70 \pm 0.22 b$ & $6.49 \pm 1.81 b$ & $7.93 \pm 6.44 b$ & 9.77 & $* * *$ \\
\hline $\mathrm{FL}, \mathrm{mm}$ & $60.13 \pm 10.89 a$ & $10.09 \pm 1.03 \mathrm{c}$ & $22.84 \pm 2.00 b$ & $22.80 \pm 5.11 b$ & 2.71 & $* * *$ \\
\hline $\mathrm{FD}, \mathrm{mm}$ & $60.90 \pm 8.68 \mathrm{a}$ & $9.89 \pm 1.18 \mathrm{c}$ & $21.60 \pm 2.32 b$ & $22.46 \pm 4.80 \mathrm{~b}$ & 2.28 & $* * *$ \\
\hline $\mathrm{TY}, \mathrm{g}$ & $1252.40 \pm 522.02 \mathrm{a}$ & $19.32 \pm 14.04 \mathrm{c}$ & $233.48 \pm 95.93 b$ & $174.23 \pm 160.79 b$ & 132.14 & $* * *$ \\
\hline $\mathrm{LN}$ & $4.10 \pm 0.86 a$ & $2.00 \pm 0.00 \mathrm{~b}$ & $2.22 \pm 0.42 b$ & $2.22 \pm 0.43 b$ & 0.35 & $*$ \\
\hline $\mathrm{SSC},{ }^{\circ} \mathrm{Bx}$ & $4.45 \pm 0.44 \mathrm{c}$ & $9.42 \pm 1.24 \mathrm{a}$ & $7.09 \pm 1.20 b$ & $6.90 \pm 1.66 b$ & 0.72 & $* * *$ \\
\hline
\end{tabular}

FW: Average fruit weight, FL: fruit length, FD: fruit diameter, TY: total yield, LN: locule number, SSC: soluble solids concentration, MSD: minimum significant difference.

Genotypes sharing same letter are equal according to Tukey test $(P<0.05)$.

${ }^{*},{ }^{* * *}$ Significant at 0.05 and 0.001 probability levels, respectively. 
and $F_{2}$ populations, respectively. In the second season, cultivated tomato and $\mathrm{F}_{2}$ showed lower values of average FW in comparison to those obtained in the first season, whereas higher values were observed in the wild parent and in the $F_{1}$ during the second season. Similar variations over the evaluations were also observed for FD and FL. Consistently, significant $(p<0.05)$ Genotype $\times$ Environment interaction was detected for these three traits. The total yield produced by $S$. lycopersicum ranged from $1238 \mathrm{~g}$ in the first evaluation to $1321 \mathrm{~g}$ in the second evaluation. In contrast, the wild parent and the $F_{2}$ showed higher values in the first season than in the second season. However, this variation over time was not explained by the Genotype $\times$ Environment interaction. Locule number remained stable through the assessments in the two seasons, so its Genotype $\times$ Environment interaction resulted not significant. On the other hand, changes over seasons were also observed on SSC, where the cultivated tomato and the $\mathrm{F}_{2}$ showed an increase in the second evaluation, while the wild tomato $S$. pimpinellifolium and the $F_{1}$ expressed a decrease in their phenotypic values. Moreover, this trait showed a non-significant Genotype $\times$ Environment effect, whereas genotype as source of variation was highly significant.

\section{Yield components}

The effects of each yield component were estimated using lineal regression, where traits such as average FW, FD, FL, LN, and total SSC were used as direct effects of yield (independent variable) on the regression model. Significant direct effects $(p<0.05)$ for all traits on the expression of yield were identified, with values ranging from $3.65 \%$ to $50.35 \%$. For the evaluation in both seasons, the average FW (40.04\% and $26.02 \%$ in the first and second evaluation, respectively), FL (50.35\% and $45.68 \%)$ and FD (42.99\% and $47.59 \%)$ were the most important yield components explaining total yield.

We also observed low explained variance values with respect to those obtained for the fruit size characters. Locule number showed the lowest significant effects on yield during two phenotypic evaluations, while the explained variance by total SSC ranged from $4.64 \%$ to $4.81 \%$. Despite the small value found for SSC, this trait can be considered as an important yield component during phenotypic selection due to the inverse relation between yield and SSC.

\section{Correlation between traits}

Highly significant $(p<0.001)$ correlations were observed between traits under a combined analysis (Figure 1). Among the fruit characters, the strongest positive correlations were observed between FW, FD, and FL ranging them from $r=0.72$ for FW and FL to $r$ $=0.89$ for FD and FL. In addition, we found extremely significant correlations $(p<0.0001)$ between TY and

\begin{tabular}{|c|c|c|c|c|c|c|}
\hline & FW & & & & & \\
\hline FL & $\begin{aligned} & 0.72 \\
&< 0.0001 \\
&\end{aligned}$ & FL & & & & \\
\hline FD & $\begin{array}{c}0.75 \\
<0.0001\end{array}$ & $\begin{aligned} & 0.89 \\
< & 0.0001\end{aligned}$ & FD & & & \\
\hline TY & $\begin{array}{c}0.52 \\
<0.0001\end{array}$ & $\begin{array}{c}0.69 \\
<0.0001\end{array}$ & $\begin{aligned} & 0.57 \\
< & 0.0001\end{aligned}$ & TY & & \\
\hline LN & \begin{tabular}{|l|}
0.14 \\
0.0124
\end{tabular} & $\begin{array}{l}0.10 \\
0.0753\end{array}$ & $\begin{array}{l}0.19 \\
0.0005\end{array}$ & $\begin{array}{l}0.11 \\
0.0409\end{array}$ & LN & \\
\hline SSC & $\begin{array}{c}-0.25 \\
<0.0001\end{array}$ & $\begin{aligned} & -0.31 \\
< & 0.0001\end{aligned}$ & $\begin{array}{c}-0.33 \\
<0.0001 \\
\end{array}$ & $\begin{aligned} & -0.24 \\
< & 0.0001\end{aligned}$ & $\begin{array}{l}-0.18 \\
0.0012\end{array}$ & SSC \\
\hline
\end{tabular}

FW: Average fruit weight, FL: fruit length, FD: fruit diameter, TY: total yield, LN: locule number, SSC: soluble solids concentration. Correlation values (upper) and $\mathrm{P}$ values (lower) are indicated in each square.

Figure 1. Significant correlations $(P<0.001)$ among traits in the $F_{2}$ population.

FW, FD, and FL. Pearson correlations between TY and fruit size traits varied from 0.52 for TY and FW to 0.69 for TY and FL. For the case of the total SSC, we found low, but extremely significant $(p<0.0001)$ negative correlations between FW, FD, FL, and TY. The value for this correlation ranged from -0.33 for SSC and FD to -0.24 for SSC and TY. We also found a highly significant $(p=0.0005)$, but low, positive correlation $(r=0.19)$ between LN and FD.

\section{QTL Analysis}

A total of 25 significant QTLs were identified for six traits of agronomic importance on the basis of single lineal regression analysis and composite interval mapping (Table 2, Figure 2). Out of the 25 detected QTLs, 17 were directly related to fruit size traits, such as FW, FD and FL. The number of QTL identified for each trait ranged from 2 (for locule number) to 9 (for fruit diameter). The number of different QTLs detected per chromosome ranged from 1 (chromosomes 6 and 7) to 3 (chromosome 1). From the seven chromosomes $(1,2,3,4,6,7$, and 11) scanned in this study, chromosome 11 show no QTLs associated to some traits. Explained variances for single QTL $(\mathrm{R}=\%$ phenotypic variation) ranged from $4.19 \%$ for the QTL for fruit diameter to $12.67 \%$ for the QTL on chromosome 3 for fruit length. The total explained variance for each trait ranged from $12.13 \%$ for total soluble solids concentration to $44.33 \%$ for fruit diameter, with genetic heritability ranging from 0.20 to 0.88 .

\section{Interactions between QTLs}

Epistatic relationships between loci were determined by means of a two-way ANOVA. With regard to average fruit weight and fruit diameter, significant interactions $(P<0.05)$ were detected (Table 3$)$. This analysis revealed a strong interaction for average fruit weight between a locus on chromosomes 1 and 3. A two-way interaction was also revealed for fruit diameter on chromosomes 1 and 3. Similarly, for this last trait, evidence of interaction was observed on chromosomes $2 \times 4$ and $3 \times 4$. Finally, an intrachromosomal interaction was also revealed on chromosomes 4 for fruit diameter. 
Table 2. Significant quantitative trait locus (QTLs) associated with yield traits detected on the $\mathrm{F}_{2}$ population.

\begin{tabular}{|c|c|c|c|c|c|c|c|c|c|c|c|c|}
\hline Trait & QTL & $\begin{array}{l}\text { Nearest } \\
\text { marker }\end{array}$ & $\mathrm{Chr}^{\mathrm{a}}$ & $\begin{array}{l}\text { Position } \\
(\mathrm{cM})\end{array}$ & $\begin{array}{l}\text { LOD } \\
\text { score }\end{array}$ & $\mathrm{R}(\%)^{\mathrm{b}}$ & $\alpha_{\mathrm{L}}^{\mathrm{c}}$ & $\alpha_{P}{ }^{c}$ & $\mid \mathrm{d} / \mathrm{al}^{\mathrm{d}}$ & $\begin{array}{c}\text { P value QTL } \times \\
\text { environment }\end{array}$ & $\begin{array}{c}\text { Total Exp } \\
\text { Variance }(\%)\end{array}$ & Heritability \\
\hline \multirow[t]{3}{*}{ FW, g } & $f w 1.1$ & TOM202 & 1 & 0.01 & 3.26 & 6.90 & 0.93 & -1.10 & 0.41 & 0.8976 & & \\
\hline & $f w 1.2$ & SSR42 & 1 & 86.95 & 4.69 & 10.43 & 1.25 & -1.20 & 0.39 & 0.9890 & & \\
\hline & fw3.1 & SSR111 & 3 & 53.00 & 4.31 & 11.23 & 1.13 & -1.23 & 0.32 & 0.4254 & 17.11 & 0.33 \\
\hline \multirow[t]{5}{*}{$\mathrm{FL}, \mathrm{mm}$} & fll.1 & TOM202 & 1 & 0.01 & 3.44 & 7.14 & 0.82 & -0.97 & 0.23 & 0.7815 & & \\
\hline & fl1.2 & SSR42 & 1 & 86.95 & 3.69 & 8.31 & 0.94 & -0.90 & 0.40 & 0.4268 & & \\
\hline & fl3.1 & SSR111 & 3 & 53.00 & 4.68 & 12.67 & 1.04 & -1.14 & 0.00 & 0.6441 & & \\
\hline & fl4.1 & SSR306 & 4 & 58.50 & 2.04 & 4.36 & 0.75 & -0.62 & 0.98 & 0.4997 & & \\
\hline & fl6.1 & SSR128 & 6 & 14.01 & 4.12 & 8.23 & 0.73 & -0.67 & 0.21 & 0.8056 & 35.29 & 0.58 \\
\hline \multirow[t]{9}{*}{$\mathrm{FD}, \mathrm{mm}$} & $f d 1.1$ & TOM202 & 1 & 0.01 & 4.61 & 10.55 & 0.95 & -1.12 & 0.07 & 0.8067 & & \\
\hline & $f d 1.2$ & SSR42 & 1 & 99.95 & 4.36 & 7.84 & 0.86 & -0.83 & 0.28 & 0.5961 & & \\
\hline & $f d 2.1$ & SSR32 & 2 & 25.00 & 4.08 & 4.92 & 0.82 & -0.71 & 0.77 & 0.6837 & & \\
\hline & $f d 3.1$ & SSR111 & 3 & 53.00 & 4.45 & 12.09 & 0.95 & -1.04 & 0.10 & 0.4278 & & \\
\hline & $f d 3.2$ & SSR320 & 3 & 115.50 & 2.50 & 8.05 & 0.71 & -0.74 & 0.35 & 0.6146 & & \\
\hline & $f d 4.1$ & SSR306 & 4 & 58.50 & 2.13 & 4.58 & 0.72 & -0.59 & 0.92 & 0.3514 & & \\
\hline & $f d 4.2$ & SSR146 & 4 & 110.10 & 2.16 & 4.19 & 0.88 & -0.78 & 0.27 & 0.4036 & & \\
\hline & $f d 4.3$ & SSR296 & 4 & 166.90 & 2.44 & 5.53 & 0.84 & -0.66 & 0.22 & 0.2477 & & \\
\hline & $f d 7.1$ & SSR45 & 7 & 117.50 & 2.01 & 5.78 & 0.66 & -0.71 & 0.65 & 0.9811 & 44.33 & 0.88 \\
\hline \multirow[t]{3}{*}{ TY, g } & ty 3.1 & SSR111 & 3 & 53.00 & 2.16 & 6.05 & 19.43 & -21.22 & 0.27 & 0.1800 & & \\
\hline & ty6.1 & SSR128 & 6 & 19.80 & 3.70 & 10.37 & 27.08 & -26.03 & 0.23 & 0.0772 & & \\
\hline & ty 7.1 & SSR45 & 7 & 117.50 & 2.47 & 6.95 & 21.10 & -22.48 & 0.67 & 0.5023 & 20.42 & 0.20 \\
\hline \multirow[t]{2}{*}{$\mathrm{LN}$} & nll.1 & SSR65 & 1 & 141.25 & 5.85 & 10.24 & 0.07 & -0.07 & 0.80 & 0.4771 & & \\
\hline & $n l 2.2$ & SSR32 & 2 & 24.41 & 3.89 & 7.38 & 0.08 & -0.07 & 0.16 & 0.4803 & 17.42 & 0.20 \\
\hline \multirow[t]{3}{*}{$\mathrm{SSC},{ }^{\circ}$ Brix } & $\operatorname{ssc} 2.1$ & TOM188 & 2 & 0.01 & 4.89 & 8.13 & -0.35 & 0.28 & 0.50 & 0.2662 & & \\
\hline & $\operatorname{ssc} 2.2$ & SSR32 & 2 & 15.41 & 4.73 & 6.94 & -0.28 & 0.24 & 0.40 & 0.0973 & & \\
\hline & $\operatorname{ssc} 3.1$ & SSR111 & 3 & 52.01 & 2.10 & 5.61 & -0.21 & 0.23 & 1.03 & 0.9752 & 12.13 & 0.26 \\
\hline
\end{tabular}

FW: Average fruit weight, FL: fruit length, FD: fruit diameter; TY: total yield; LN: locule number; SSC: soluble solids concentration.

aChromosome on which QTL was detected.

bercentage of phenotypic variation explained by the QTL.

${ }^{\mathrm{c}}$ Average allelic effect provided by Solanum lycopersicum and S. pimpinellifolium.

${ }^{\mathrm{d}}$ Degree of dominance expressed by the QTL.

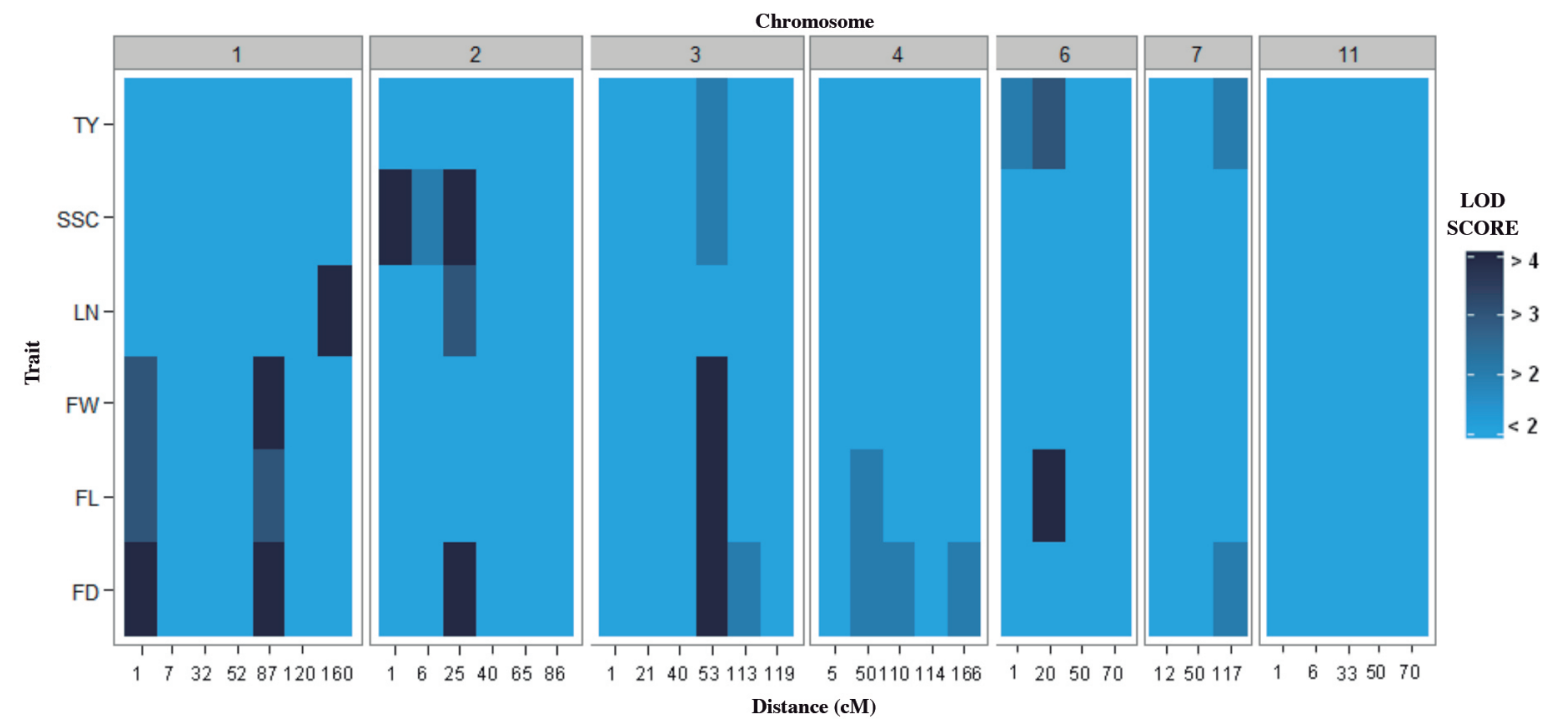

TY: Total yield, SSC: soluble solids concentration, LN: locule number, FW: average fruit weight, FL: fruit length, FD: fruit diameter.

Figure 2. Heatmap of quantitative trait locus (QTLs) identified for yield-related traits.

Table 3. Two-locus interactions identified for yield-related components at the genome-wide level $(P<0.05)$.

\begin{tabular}{llcccccc}
\hline Trait & QTL & Chromosome & Position $(\mathrm{cM})$ & QTL & Chromosome & Position $(\mathrm{cM})$ & P value \\
\hline FW & $f w 1.2$ & 1 & 86.95 & fw3.1 & 3 & 53 & $* * *$ \\
FD & $f d 1.1$ & 1 & 0.01 & fd 3.1 & 3 & 53 & $*$ \\
FD & $f d 2.1$ & 2 & 25 & fd4.1 & 4 & 58.5 & $*$ \\
FD & $f d 3.1$ & 3 & 53 & fd4.3 & 4 & 166.9 & $*$ \\
FD & $f d 4.1$ & 4 & 58.5 & fd4.2 & 4 & 110.1 & $*$ \\
\hline
\end{tabular}

FW: Average fruit weight, FD: fruit diameter, QTLs: quantitative trait locus, cM: centimorgan.

${ }^{*}, * *$ Significant at 0.05 and 0.001 probability levels, respectively. 


\section{DISCUSSION}

In this study we found a wide variation between the parents for all tested traits. Average FW showed the most striking divergence between the two parents, where the fruit of S. pimpinellifolium averaged $0.7 \mathrm{~g}$ in both seasons, S. lycopersicum presented an average FW of $120.8 \mathrm{~g}$. In addition to FW differences between parents, different levels of dominance of the wild parent was observed in both the $F_{1}$ and $F_{2}$ populations in most of the fruit traits. These results are in agreement with those reported by classical studies, in which $F_{1}$ hybrids resulting from a cross between a large and small-fruited cultivar typically exhibited similar characteristics to those of the smallerfruited parent (Hernández-Bautista et al., 2014). In this regard and according to Tanksley (2004), the explanation for this dominance could be fitness of each allele. Thus, in wild tomatoes, tomato fruit are adapted for seed dispersal, therefore, a small fruit may provide an advantage over a large fruit for dispersal, because they can be readily removed, carried, and dispersed by biotic and abiotic factors.

Yield components evaluated on this study showed a significant effect on the expression of yield on $\mathrm{F}_{2}$ populations. Fruit length and fruit diameter were the major yield components according to our results, which indicate that these traits are relevant yield components to be used as the selection criteria for improving tomato yield (Rashidi et al., 2009). Due to a high positive correlation detected among fruit size traits, average FW also had a similar effect on yield to that one obtained for FL and FD. These results are in agreement with those of Rahaman and Bhatt (2013), who concluded that fruit size traits are the most important yield components in tomato. Although in several studies it has been reported that fruit size has a low interaction with the environment due to its low genetic complexity (Foolad, 2007), we found a high significant Genotype $\times$ Environment interaction on fruit size traits. On the other hand, SSC and LN showed a minor effect upon yield, indicating that these traits play a complementary role on the expression of yield.

In this study, a total of 25 QTLs were detected for six traits using an $F_{2}$ population. All of the QTLs had their effects in the expected direction based on the parental phenotypes. QTLs with a major effect were identified on fruit size traits on linkage groups 1 and 3, displaying a gene action from additivity to partial dominance of the wild alleles over the lycopersicum alleles.

Fruit size is one of the most important traits for tomato breeding. A wide diversity of fruit into the cultivated tomato is evident, despite of little genetic variation contained in its genome (van der Knaap et al., 2013). It has been suggested that exceptionally large-fruited tomato varieties were evolved as a result of novel combinations of major QTLs (Tanksley, 2004; Foolad, 2007). Several molecular mapping studies have been carried out to identify QTLs for fruit size of tomato involving interspecific crosses between cultivated tomato and wild species (Grandillo and Tanksley, 1996; Chen et al., 1999; Lippman and Tanksley, 2001; Doganlar et al., 2002). Those studies have revealed the presence of at least 28 QTLs for fruit weight in tomato (Ariizumi et al., 2013), some of which with very large effects $(f w 1.1, f w 2.1, f w 2.2$, $f w 3.1, f w 3.2, f w 11.3$ ) (Zhang et al., 2012). In our study we identified three $(f w 1.1, f w 1.2$, and $f w 3.1)$ of those six major QTL for fruit weight. In spite of FW, FD, and FL are related traits, we detected a different number of QTLs for average FW (3 QTLs), FD (9 QTLs), and FL (5 QTLs), as well as for the individual and total explained variance for average $\mathrm{FW}(\mathrm{TV}=17.11 \%)$, FD $(\mathrm{TV}=44.33 \%)$, and FL $(\mathrm{TV}=35.29 \%)$. We also observed that the three QTLs ( $f w 1.1, f w 1.2$, and $f w 3.1)$ controlling average FW occupied similar positions with the QTLs for FL and FD. This clustering of QTLs influencing the 3 characters is in agreement with the strong positive correlation found between average FW and FL $(r=0.72)$ and between average FW and FD $(r=0.75)$. These results are similar with those reported by Doganlar et al. (2002), who found 16 QTL having a significant effect on more than one trait and also found significant correlations among fruit size traits. Additionally, our data tend to support the idea proposed by Doganlar et al. (2002) and Khan et al. (2012), who concluded that the colocalization of QTLs and the correlations among traits could be caused by pleiotropic effects of the same genes rather than linkages of independent genes.

Recently, the obtaining of large-fruited varieties with high SSC has been one important goal in tomato breeding programs. However, several studies have found a negative correlation between SSC and TY (Chen et al., 1999; Monamodi et al., 2013), as it was found in our study $(r=-0.24)$. This has caused that breeders have had little success in obtaining of high-yielding tomato varieties with high SSC using traditional phenotypic selection. Currently, there are more than 20 published studies that have identified QTLs for high fruit SSC in tomato (Foolad, 2007), and near of 63 genes putatively involved in C metabolism have been identified (Causse et al., 2004; Fernie et al., 2006). This number of genes is not surprising considering the very complex nature of the trait and its low heritability. Besides the strong negative correlation between total solids content and FW, many studies have revealed that QTLs that positively influence SSC are mostly at the same chromosomal locations as QTLs that negatively impact fruit size (Grandillo and Tanksley, 1996). Similar results were found in our data, where the QTL named fw3.1 for FW was co-locating with one QTL detected for total solids content. Moreover, we also 
found co-location of one QTL for LN (nl2.2) with another QTL (ssc2.2) controlling total soluble solids. All QTLs for total soluble solids were detected on chromosomes 2 and 3, in addition, these QTLs explained $12.13 \%$ of the total phenotypic variation, and none of the 3 QTLs had a phenotypic variance explained value greater than $10 \%$. In spite of a significant correlation between yield and SSC found in this study, none of these QTLs were co-locating with the QTLs for yield. This suggested that the effect of the SSC detected on yield was caused by fruit weight QTLs linked to soluble solids loci rather than a direct effect of the genes controlling the SSC.

With regard to yield QTLs, these co-localized with QTLs identified for average FW ( $f w 3.1)$, FD ( $f d 7.1)$ and FL (f6.1). This co-localization is consistent with the significant correlations between these traits. Besides the co-localizations previously commented, we also observed that due to the high effects of the fruit size traits on yield, the three QTLs detected for yield could be the same QTLs identified for FD, FL and FW, which indicates that these three QTLs play a role in the same genetic process controlling yield. In spite of the co-localizations of QTLs among the yield and fruit size traits, we observed different values of explicated variance from these QTLs; fw3.1 showed a greater effect on fruits size traits than on yield, while $f 6.1$ and $f d 7.1$ had a greater effect upon yield than on FL and FD.

\section{CONCLUSIONS}

The strong effects by fruit diameter, fruit length, and fruit weight on yield, along with the co-location of quantitative trait locus (QTL) among yield and fruit size traits evidenced that fruit size QTLs have a strong effect on the yield of tomato. On the other hand, we observed small significant effects of locule number and soluble solids content on the expression of yield. However, the effects of soluble solids concentration on yield could be due to direct effects of fruit size QTLs linked to genes controlling soluble solids content. This then suggests that tomato yield is mainly controlled by QTLs of fruit size, where the remaining factors play a complementary role for the expression of tomato yield. With regard to the limited concordance of yield QTLs across studies, our hypothesis is that this limited concordance is because yield QTLs belong to different yield components. So if the main yield components are not phenotyped on the study, QTLs detected for yield will show this problem. Thus, our study on tomato yield has provided new knowledge about its genetic basis. This knowledge could improve efficiency of selection process for obtaining of large-fruited varieties with high yield. Molecular markers linked to the QTLs for yield found in this study could be utilized on marker assisted selection due to strong co-colocation with fruit size QTLs. Furthermore, novels QTLs for fruit size were found in this study, so we will work them with fine-mapping to elucidate the molecular mechanisms that control the yield.

\section{ACKNOWLEDGEMENTS}

We would like to thank The Colegio de Postgraduados, LPI-6, and CONACYT (Mexico) for financing this work.

\section{LITERATURE CITED}

Acquaah, G. 2007. Principles of plant genetics and breeding. Blackwell Publishing, Oxford, UK.

Ariizumi, T., Y. Shinozaki, and H. Ezura. 2013. Genes that influence yield in tomato. Breeding Science 63:3-13.

Bernacchi, D., T. Beck-Bunn, Y. Eshed, J. Lopez, V. Petiard, H. Sayama, et al. 1998. Advanced backcross QTL analysis in tomato. Theoretical and Applied Genetics 97:381-397.

Bernatzky, R., and S.D. Tanksley. 1986. Methods for detection of single or low copy sequences in tomato on Southern blots. Plant Molecular Biology Reporter 4:37-41.

Causse, M., P. Duffe, M.C. Gomez, M. Buret, R. Damidaux, D. Zamir, et al. 2004. A genetic map of candidate genes and QTLs involved in tomato fruit size and composition. Journal of Experimental Botany 55:1671-1685.

Chen, F.Q., M.R. Foolad, J. Hyman, D.A. St. Clair, and R.B. Beelaman. 1999. Mapping of QTLs for lycopene and other fruit traits in a Lycopersicon esculentum $\times$ L. pimpinellifolium cross and comparison of QTLs across tomato species. Molecular Breeding 5:283-299.

Creste, S., A. Tulmann Neto, and A. Figueira. 2001. Detection of single sequence repeat polymorphisms in denaturing polyacrylamide sequencing gels by silver staining. Plant Molecular Biology Reporter 19:299-306.

Diez, M.J., and F. Nuez. 2008. Tomato. p. 249-323. In Prohens, J., and F. Nuez (eds.) Vegetables II. Handbook of plant breeding. Vol. 2. Springer, New York, USA.

Doganlar, S., A. Frary, H.M. Ku, and S.D. Tanksley. 2002. Mapping quantitative trait loci in inbred backcross lines of Lycopersicon pimpinellifolium (LA1589). Genome 45:1189-1202.

Eshed, H., and D. Zamir. 1995. An introgression line population of Lycopersicon pennellii in the cultivated tomato enables the identification and fine mapping of yield-associated QTL. Genetics 141:1147-1162

Fernie, A.R., Y. Tadmor, and D. Zamir. 2006. Natural genetic variation for improving crop quality. Current Opinion in Plant Biology 9:196-202.

Fogle, H.W., and T.M. Currence. 1950. Inheritance of fruit weight and earliness in a tomato cross. Genetics 35:363-380.

Foolad, M.R. 2007. Genome mapping and molecular breeding of tomato. International Journal of Plant Genomics 2007:1-52.

Frary, A., T.M. Fulton, D. Zamir, and S.D. Tanksley. 2004. Advanced backcross QTL analysis of a Lycopersicon esculentum $\times L$. pennelli cross and identification of possible orthologs in the Solanaceae. Theoretical and Applied Genetics 108:485-496.

Grandillo, S., and S.D. Tanksley. 1996. QTL analysis of horticultural traits differentiating the cultivated tomato from the closely related species Lycopersicon pimpinellifolium. Theoretical and Applied Genetics 92:935-951.

Hall, D., C. Tegstrom, and P.K. Ingvarsson. 2010. Using association mapping to dissect the genetic basis of complex traits in plants. Briefings in Functional Genomics 9:157-165.

Hernández-Bautista, A., R. Lobato-Ortiz, S. Cruz-Izquierdo, J.J. García-Zavala, y J.L. Chávez-Servia. 2014. Variación fenotípica, heterosis y heredabilidad de una cruza interespecífica de jitomate. Interciencia 39:327-332.

Heuvelink, E., and M. Dorais. 2005. Crop growth and yield. p. 85-144. In Heuvelink, E. (ed.) Tomatoes. CABI Publishing, Cambridge, Massachusetts, USA. 
Khan, N., R.H. Kazmi, L.A.J. Willems, A.W. van Heusden, W. Ligterinkn, and H.W.M. Hilhorst. 2012. Exploring the natural variation for seedling traits and their link with seed dimensions in tomato. PloS One 7(8):e43991.

Kosambi, D.D. 1944. The estimation of map distances from recombination values. Annals of Eugenics 12:172-175.

Lippman, Z., and S.D. Tanksley. 2001. Dissecting the genetic pathway to extreme fruit size in tomato using a cross between the small-fruited wild species Lycopersicon pimpinellifolium and $L$. esculentum var. Giant Heirloom. Genetics 158:413-422.

Lorieux, M. 2012. MapDisto: fast and efficient computation of genetic linkage. Molecular Breeding 30:1231-1235.

Monamodi, E.L., D.M. Lungu, and G.L. Fite. 2013. Analysis of fruit yield and its components in determinate tomato (Lycopersicon lycopersci) using correlation and path coefficient. Botswana Journal of Agriculture and Applied Sciences 9:29-40.

Muños, S., N. Ranc, E. Botton, A. Bérard, S. Rolland, P. Duffé, et al. 2011. Increase in tomato locule number is controlled by two single-nucleotide polymorphisms located near WUSCHEL. Plant Physiology 156:2244-2254.

Poehlman, J.M., and D.A. Sleper. 1995. Breeding field crops. Iowa State University Press, Ames, Iowa, USA.

R Core Team. 2013. R: A language and environment for statistical computing. R Foundation for Statistical Computing, Vienna, Austria.

Rahaman, S., and J.S. Bhatt. 2013. Path co-efficient analysis of yield component in tomato. International Journal of Agriculture Science 9:227-231.

Rashidi, M., M. Gholami, and B.G. Khabbaz. 2009. Response of yield and yield components of tomato (Lycopersicon esculentum) to different tillage methods. International Journal of Agriculture and Biology 11:626-630.
Robbins, M.D., S.C. Sim, W. Yang, A. Van Deynze, E. Van der Knaap, T. Joobeur, et al. 2011. Mapping and linkage disequilibrium analysis with a genome-wide collection of SNPs that detect polymorphism in cultivated tomato. Journal of Experimental Botany 6:1831-1845.

Rodríguez, G.R., S. Muños, C. Anderson, S. Sim, A. Michel, M. Causse, et al. 2011. Distribution of SUN, OVATE and FAS in the tomato germplasm and the relationship to fruit shape diversity. Plant Physiology 156:275-285.

Stuber, C.W., M.D. Edwards, and J.F. Wendel. 1987. Molecular marker-facilitated investigation of quantitative trait loci in maize. II. Factors influencing yield and its component traits. Crop Sciences 27:639-648.

Tanksley, S.D. 2004. The genetic, developmental, and molecular bases of fruit size and shape variation in tomato. Plant Cell 16:S181-S189.

van der Knaap, E., C. Anderson, and G. Rodriguez. 2013. Diversity within cultivated tomato. p. 77-88. In Liedl, B.E., J.A. Labate, J.R. Stommel, A. Slade, and C. Kole (eds.) Genetics, genomics and breeding of tomato. CRC Press, Boca Raton, Florida, USA.

Wang, S., C.J. Basten, and Z.B. Zeng. 2012. Windows QTL Cartographer V2.5. Department of Statistics, North Carolina State University, Raleigh, North Carolina, USA. Available at http://statgen.ncsu.edu/qtlcart/WQTLCart.htm (accessed October 2014).

Zeng, Z.B. 1994. Precision mapping of quantitative trait loci. Genetics 136:1457-1468.

Zhang, N., M.T. Brewer, and E. van der Knaap. 2012. Fine mapping of fw3.2 controlling fruit weight in tomato. Theoretical and Applied Genetics 125:273-284. 